\title{
O PROCESSO DE INDUSTRIALIZAÇÃO NA DÉCADA DE 1960 E AS TRANSFORMAÇÕES DA PAISAGEM URBANA NO BAIRRO DA PRATA, EM CAMPINA GRANDE
}

\author{
Alcilia Afonso de Albuquerque e Melo \\ Universidade Federal de Campina Grande. UFCG. CAU. UAEC. CTRN \\ Email: kakiafonso@hotmail.com
}

\begin{abstract}
RESUMO
Esse texto possui como objeto de estudo, o papel da industrialização no desenvolvimento urbano do bairro da Prata, na cidade de Campina Grande- agreste do estado da Paraíba, nordeste brasileiro- durante a década de 1960. A investigação vem sendo desenvolvida pelo grupo de pesquisa Arquitetura e Lugar, do programa de pós graduação em história da UFCG/ Universidade Federal de Campina Grande, integrada com o curso de arquitetura e urbanismo da mesma instituição, e está inserida na linha voltada para história e cidade, trabalhando com a construção da história urbana campinense, relacionando conceitos de cidade, patrimônio industrial e modernidade. O objetivo é analisar a importância da industrialização no crescimento da cidade durante esse recorte temporal, observando as relações entre os diversos atores urbanos na construção de um cenário de modernidade. Como metodologia optou-se por trabalhar com uma linha de pesquisa arquitetônica e urbanística proposta por Serra (2006) que propõe o diálogo entre processo e sistemas.
\end{abstract}

Palavras chaves: patrimonio industrial; SUDENE; interferência na configuração da cidade

\section{ABSTRACT}

This paper aims to study the role of industrialization in the urban development of the district of Prata, in the city of Campina Grande- "agreste" in the state of Paraíba, Northeastern Brazil, during the 1960s. Research has been carried out by the research group Architecture and Place, UFCG / Universidade Federal de Campina Grande, integrated with the course of architecture and urbanism of the same institution, and is inserted in the line directed to history and city, working with the construction of the urban history, relating concepts of City, industrial patrimony and modernity. The objective is to analyze the importance of industrialization in the growth of the city during this temporal cut, observing the relations between the different urban actors in the construction of a scenario of modernity. As a methodology, it was decided to work with a line of architectural and urban research proposed by Serra (2006), who proposes the dialogue between process and systems.

Key words: Industrial heritage; SUDENE; Interference in the configuration of the city 


\section{INTRODUÇÃO}

Esse texto tratará sobre o papel da industrialização no desenvolvimento urbano da cidade do bairro da Prata, na Campina Grande- agreste do estado da Paraíba, nordeste brasileiro- durante a década de 1960, tomando como estudo de caso, o bairro da Prata, situado ao lado da área central urbana. Portanto, é um texto que dialogará com o eixo temático 5 , desse evento, voltado para as discussões sobre as análises e ordenação da paisagem e transformações urbanas.

A pesquisa vem sendo realizada pelo grupo de pesquisa Arquitetura e Lugar, do programa de pósgraduação em história da UFCG/ Universidade Federal de Campina Grande, integrada com o curso de arquitetura e urbanismo da mesma instituição, e está inserida na linha de pesquisa voltada para história e cidade. Possui como objeto de estudo, o papel da industrialização no desenvolvimento urbano da cidade de Campina Grande- agreste do estado da Paraíba, nordeste brasileiro- durante a década de 1960.

O objetivo da pesquisa que está em desenvolvimento é comprovar o papel da industrialização no desenvolvimento urbano de Campina Grande durante a década de 1960, observando as relações existentes entre os diversos atores urbanos: empresários, políticos, profissionais liberais, operários- na construção de um cenário de modernidade urbana e arquitetônica, que utilizou a antiga área de uma fazenda, o bairro da Prata, para instalar ali, os equipamentos e as residências modernas que simbolizavam a ascensão econômica de uma cidade que crescia. Possui como objetivos específicos, observar o estado de conservação em que se encontra o acervo reminiscente, bem como, analisar que medidas vêm sendo tomadas pelos órgãos competentes para inserir o mesmo no planejamento urbano local.

\section{HIPÓTESES}

A pesquisa vem trabalhando com a hipótese de que a industrialização pela qual passou a política econômica regional na década de sessenta do século XX colaborou para a criação de novos bairros na cidade, e para tanto, toma como exemplo, o bairro da Prata- área que possui ainda um rico acervo moderno, composto por escolas, clubes, residências. Observou-se que nos anos 20 e 30, o ciclo econômico do algodão, foi o responsável pelo projeto e construção de uma cidade com linhas Art Dèco- e tal afirmativa foi objeto de estudos de pesquisas que comprovaram tal fato (QUEIROZ, 2016).

Mas, o que teria causado o "boom" moderno na cidade e como explicar a existência de um acervo grande e rico, contando com a presença de arquitetos de outras cidades, e fazendo surgir ali, novos nomes que colaboraram para a construção dessa cidade moderna?

Para observar a interferência da industrialização na construção de um cenário moderno urbanístico e arquitetônico, e a fim de procurar esclarecer ou comprovar a hipótese em pauta, alguns questionamentos foram realizados, a saber: 1) De que forma o processo de industrialização- ocorrido na década de 1960 na cidade de Campina Grande, incentivado pela política da SUDENE/ Superintendência do Desenvolvimento do Nordeste, interferiu na construção de uma cidade moderna; 2) Qual foi a origem do bairro da Prata no traçado urbano e como se configurou a arquitetura de linguagem moderna? ; 3) Como se deu a relação entre políticas públicas, empresariado e a população local nessa década?; 4) Que edificações marcaram esse período como símbolos do discurso de modernidade e industrialização?; 5) Que medidas preservacionistas vêm sendo tomadas para se conservar o acervo?

\section{METODOLOGIA DA PESQUISA}

Para responder a tais questionamentos, optou-se por trabalhar com duas linhas metodológicas: A primeira linha que é voltada para um trabalho teórico de pesquisa arquitetônica e urbanística- através da coleta de dados primários e secundários, baseando-se principalmente, no que propõe SERRA (2006), quando caracteriza processos e sistemas na elaboração de pesquisas científicas em Arquitetura e Urbanismo. A segunda linha trabalha especificamente com a análise dos edifícios que compõem esse cenário urbano, e se apoia para tanto em um método proposto por GASTÓN e ROVIRA (2007), do grupo de pesquisa FORM/ UPC/ Universidade Politécnica da Catalunha, que parte do estudo gráfico projetual, realizando imagens fotográficas, levantamento de material de projeto, como plantas, cortes, fachadas e construções tridimensionais, que permitem a melhor compreensão do objeto em estudo.

A primeira linha metodológica apoia-se em Serra, que em seu livro intitulado "Pesquisa em Arquitetura e urbanismo/ Guia prático para o trabalho de pesquisadores em pós-graduação" (2006) discorreu sobre o tema da metodologia da pesquisa, afirmando que o método implica, antes de tudo, em atividades 
ordenadas, tarefas colocadas sequencialmente e a partir de um plano de ação racional. $\mathrm{O}$ autor entende por processo, "o modo como se sucedem os estados diferentes do sistema no tempo". (Serra, 2006, p.72), e por sistemas, "um conjunto de objetos entendidos como uma totalidade de eventos, pessoas ou ideias que interagem uns com os outros". (Serra, 2006, p.70). Estes são representados por seu contorno, por uma definição ou pela enumeração dos elementos que o compõem, como também pelas interações entre eles e entre o sistema e seu entorno. (Figura 1)

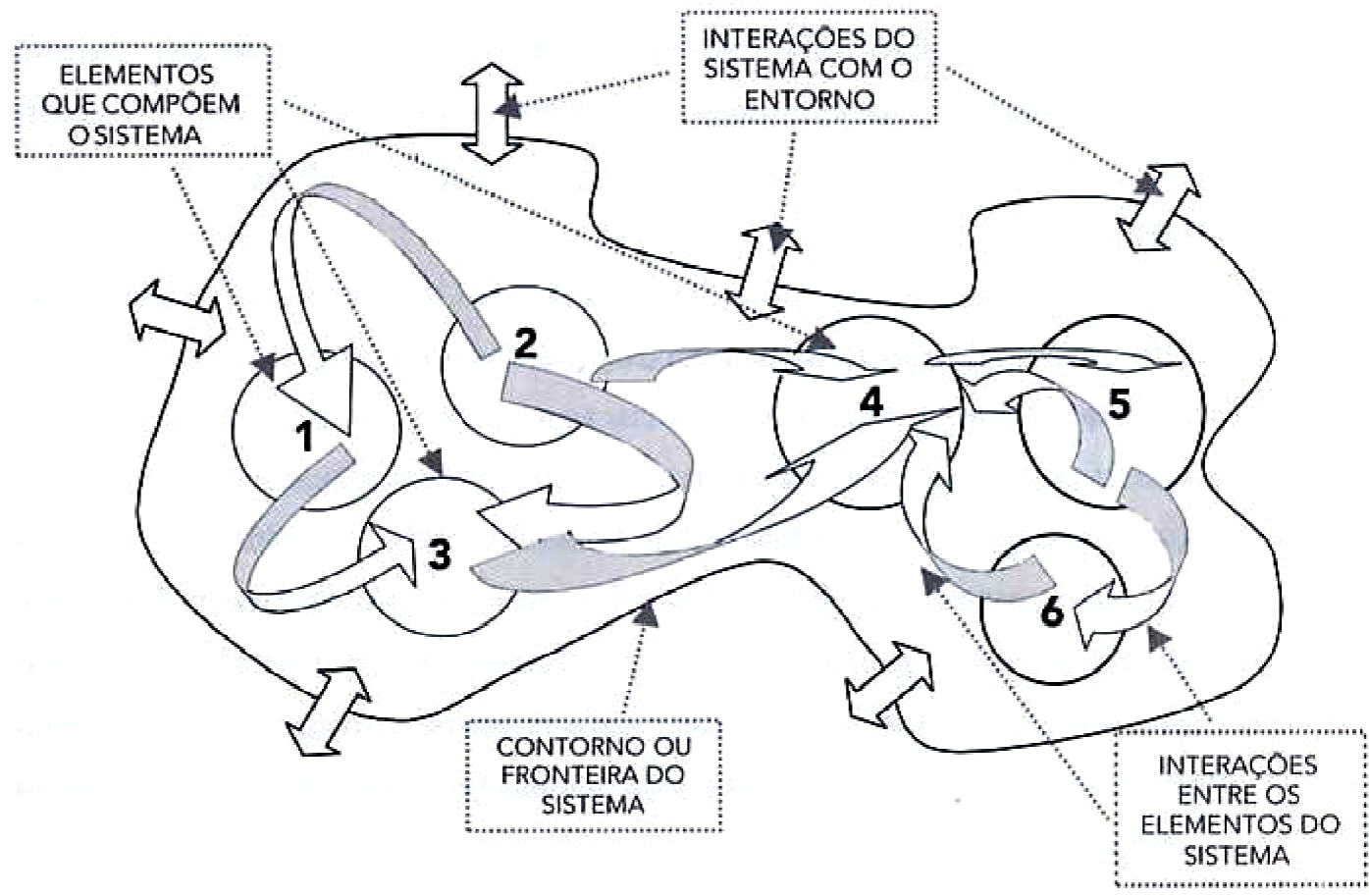

Figura 1: Esquema da metodologia de pesquisa. Fonte: Serra, 2006, p.70

Dessa forma, a metodologia trabalhada, procura entender os processos e investigar as causas das mudanças pelas quais o sistema está passando. Vale ressaltar que, os procedimentos metodológicos realizados neste primeiro momento são de caráter mais analítico e descritivo. Registros fotográficos, visitas in loco e aplicação de fichas de observação da cidade e das obras que compõem o objeto de estudo. Nessa fase, estuda-se a área do bairro Prata, destinando esforços para levantar informações necessárias a comprovar a hipótese em pauta.

Assim, pode-se compreender que na metodologia proposta por Serra, tem-se como processo em estudo- o papel da industrialização no desenvolvimento urbano de Campina Grande durante a década de 1960permeado por um sistema de fatos e acontecimentos que se relacionam entre si, interagindo e construindo um fio condutor que acarreta na compreensão do que pode ter ocorrido para a concretização da construção da cidade moderna.

Nessa metodologia, os aspectos sociais, políticos, culturais, econômicos, são compreendidos como caminhos que se cruzam e giram em torno do processo que ocorria e que resultou no cenário que foi construído e consolidado em Campina Grande.

A segunda linha metodológica apoia-se em GASTÓN e ROVIRA (2007), que elaboraram um guia básico de investigação sobre o projeto de arquitetura moderna, cujo objetivo é o de facilitar a análise critica e arquitetônica dos objetos estudados, apresentando ferramentas para operar o material documental de maneira eficiente, assim como, ilustrar o modo mais adequado de elaborar e apresentar as conclusões.

O método proposto visa com que o pesquisador coloque-se no lugar do arquiteto para refazer o processo de concepção da obra, descobrindo o que há condensado em cada decisão, esclarecendo o argumento interno que lhe dá coesão. 
"En definitiva, adquirir una comprensión activa de la historia para avivar los mejores proyectos de la cultura moderna. Acreditar la continuidad de los valores estéticos vigentes y que se pueden alumbrar la práctica de la arquitectura al restablecerlos efectivamente en relación con las posibilidades técnicas y productivas actuales". GASTÓN e ROVIRA (2007, p. 34)

Para obterem-se as informações necessárias para a construção da pesquisa, tem sido fundamental a consulta em fontes primárias e secundárias. A coleta de dados vem sendo realizada em arquivos da Federação das Indústrias do Estado da Paraíba/ FIEPB, nos arquivos municipais, em arquivos da SUDENE/ Superintendência do Desenvolvimento do Nordeste, bem como, a realização de entrevistas com pessoas que vivenciaram tal período- utilizando-se para isso, de ferramentas da história oral (Portellli, 2009).

As visitas de campo ao bairro da Prata vêm sendo realizadas, a fim de se buscar nas ruas, nos edifícios, nos lugares, os arquivos da história urbana local.

\section{APORTE TEÓRICO}

A pesquisa trabalha com a construção da história urbana campinense, relacionando conceitos de cidade, patrimônio industrial e modernidade. Apoia-se para tanto, em um referencial teórico voltado para o conceito de cidade- compreendida como o arquivo da história, conforme colocou GOITIA (2011), que colocou que "é no espaço urbano, que se encontra edificado o patrimônio arquitetônico de uma sociedade, que guarda a memória coletiva de vários indivíduos, ou grupos, através da construção de edificações, ruas, praças, lugares de memória".

O conceito de patrimônio cultural vem passando por constante evolução, em rápida expansão e mudança, conforme observou CASTRIOTA (2007), que escreveu que o tema está em voga, e que nunca havia tido, anteriormente, tantos instrumentos para se lidar com as pré- existências culturais. Colocou o autor que: "Entramos no século XXI com o patrimônio ocupando um papel central na reflexão não só sobre a cultura, mas também nas abordagens que hoje se fazem do presente e do futuro das cidades, do planejamento urbano e do próprio meio ambiente".

A discussão sobre patrimônio industrial, por sua vez, recebeu um incremento a partir da publicação da Carta de Nizhny Tagil (2003), quando esta apontou para a importância de se preservar o acervo composto pelas antigas fábricas, galpões de armazenamento, entrepostos, escritórios, estações ferroviárias, que se encontram abandonados nas periferias, e mesmo nos centros urbanos de nossas cidades, quase sempre ameaçados de serem demolidos, em vista da ausência do reconhecimento do valor dessas estruturas como patrimônio cultural.

O resgate documental, imagético, realização de inventários, ações de educação patrimonial, proteção legal, entre outras ações importantes são algumas etapas do processo que urge ser iniciado em nossas cidades e em seus planejamentos urbano e territorial.

ZANCHETTI (2002) apontou para a necessidade do diálogo entre cidade, patrimônio cultural na contemporaneidade, interagindo planejamento urbano e territorial, e propôs uma discussão sobre o conceito de conservação integrada, como um caminho a ser seguido para a salvaguarda dos acervos patrimoniais: "Conservação integradal Cl é uma um modo de abordar o planejamento e a gestão do patrimônio cultural urbano segundo alguns princípios, sugerindo que o planejamento e a gestão de áreas urbanas de interesse patrimonial devem estar integradas nos processo mais gerais de planejamento e gestão das cidades e dos territórios, dentro de uma visão multidimensional integrada (econômica, política, cultural, ambiental e físicoespacial);"

$\mathrm{Na} \mathrm{Cl}$, conservação é entendida como uma forma especial do processo de transformação urbana que procura manter no tempo (intergerações) a integridade e a autenticidade do patrimônio cultural.

A questão é que infelizmente, o acervo patrimonial industrial e moderno, ainda não é devidamente valorizado e reconhecido pela política preservacionista nacional, estando fora da listagem de bens inventariados, ou protegidos por leis, por parte dos órgãos de preservação existentes no país, no estado e no município. Portanto, esse acervo decorrente desse período histórico de urbanização, encontra-se desprotegido e sofre diariamente perdas irreparáveis para a preservação da história urbana de Campina Grande. 


\section{CONTEXTO}

Antes de enfocar o processo de industrialização em Campina Grande nos anos 60 e a interferência desse sob a urbanização local, importante é contextualizar o cenário nacional em termos dos acontecimentos sócio culturais, políticos e econômicos, a fim de observar de que maneira tais fatos incidiram no local.

\subsection{Contexto Histórico: os anos 60 do século XX no Brasil.}

No Brasil, a década de 60 do século XX, iniciou-se com um dos fatos mais marcantes na área da arquitetura e do urbanismo nacional, que foi a inauguração de Brasília. A transferência da capital do Brasil do litoral carioca para o interior era ideia antiga, que remontava à Inconfidência Mineira e ganhara força na época da Independência. Mas foi apenas em 21 de abril de 1960, com a inauguração da cidade, que o sonho se concretizou. Fincada no meio do Planalto Central, Brasília foi prometida pelo presidente Juscelino Kubitschek (1956 a 1961) logo após sua posse, em janeiro de 1956.

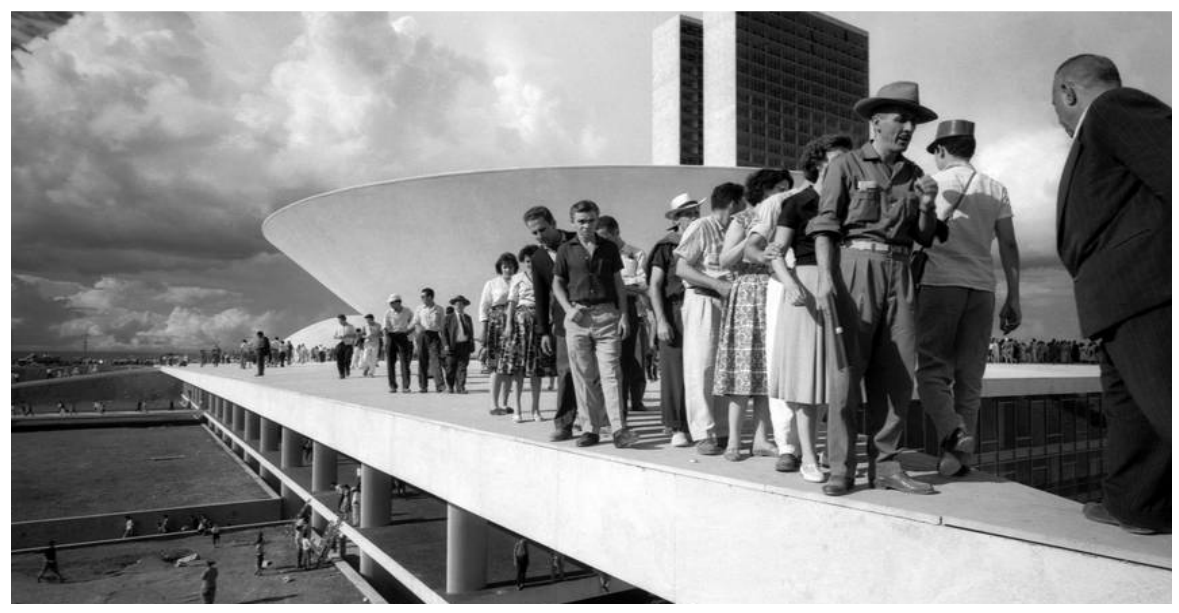

Figura 2: Construção de Brasília, no dia de inauguração. Fonte: Acervo Instituto Moreira Salles

A cidade com sua arquitetura moderna tornou-se um paradigma para demais cidades brasileiras, influenciando vários arquitetos nacionais com a linguagem plástica do arquiteto Oscar Niemeyer, colaborando de forma contundente para a difusão da modernidade arquitetônica no país.

Politicamente, o Brasil passou naquela época, por momentos difíceis: Em $1^{\circ}$ de abril de 1964, o então presidente do Brasil, João Goulart, foi deposto por um golpe militar. Assumiu o governo, o presidente da Câmara dos Deputados, Ranieri Mazzilli. Em 15 de abril, o marechal Humberto de Alencar Castelo Branco, assumiu a presidência e foi divulgada uma lista de cassação de direitos políticos composta por 72 nomes, entre os quais parlamentares e oficiais do Exército leais ao ex-presidente João Goulart, exilado do país.

Teve início então, a ditadura militar que tinha como principais características a cassação de direitos políticos de opositores, a repressão aos movimentos sociais e manifestações de oposição, a censura aos meios de comunicação e aos artistas, aproximação dos EUA (controle dos sindicatos), implantação do bipartidarismo: ARENA (governo) e MDB (oposição controlada), enfrentamento militar dos movimentos de guerrilha contrários ao regime militar, uso de métodos violento, inclusive tortura contra os opositores ao regime, milagre econômico: forte crescimento da economia com altos investimentos em infraestrutura, acarretando um aumento da dívida externa.

O professor da USP/ Universidade de São Paulo, NAPOLITANO (2014), em obra publicada tratou de expor de forma esclarecedora um balanço histórico do regime militar brasileiro, conhecido como os "anos de chumbo", trazendo à tona informações sobre os aspectos sociais, políticos e culturais desse período. Baseado nessas informações pode-se afirmar que a década de 60 no Brasil foi composta por fatos contraditórios, como golpe militar, agitação cultural, passeatas estudantis de 1968, milagre econômico, guerrilha de esquerda, repressão, tortura, abertura política.

Esta época foi reconhecida como tempo de mudanças- uma década marcada pela repressão, censura e violência. Um período que, no âmbito político, foi marcado pela falta de democracia a qual promoveu transformações na estrutura da produção e da sociedade, nos comportamentos políticos e nas 
manifestações culturais. Lutava-se contra o regime de ditadura militar implantada em 1964, contra a reforma educacional, o que mais tarde provocou o fechamento do Congresso e na decretação do Ato Institucional no 5- decretado no dia 13 de dezembro de 1968, o General Arthur da Costa e Silva- que implantou o recesso do Congresso Nacional, fazendo com que o governo passasse a ter poderes absolutos sobre a nação. Com o recesso, o Executivo ficou autorizado a legislar, suspender os direitos políticos de qualquer cidadão e cassar mandatos parlamentares. O regime militar começou a perseguir líderes sindicalistas e estudantis que apoiavam o presidente deposto, dos quais eram torturados e até mesmo mortos. As manifestações artísticas passam a ser censuradas e muitos artistas passam a optar pelo exílio ou ao silêncio.

Segundo NAPOLITANO (2014, p.8), os movimentos sociais, vigiados e reprimidos, conforme a lógica de segurança nacional, não desapareceu. Muito pelo contrário, tornaram-se diversos e complexos, expressão de uma sociedade que não ficou completamente passiva diante do autoritarismo.

Por isso, pode-se afirmar que a década de 60 também foi um ano de revolução na cultura brasileira: na música surgiu o Tropicalismo e a Jovem Guarda. Na área cinematográfica, foi criado o cinema novo, cujo principal diretor foi Glauber Rocha, que obteve reconhecimento internacional ao ser premiado durante o Festival de Cannes, em 1967, com o filme "Terra em Transe".

A informação era dominada pelo rádio e pela televisão que influenciou diretamente na transformação dos costumes: o país foi palco de grande expansão da massificação das informações e dos padrões de comportamento de consumo. A televisão foi o principal veículo que penetrou de forma incomparável numa década em que as redes de telecomunicações atingiram distantes regiões do país, atingindo a todas as camadas sociais. Esse papel tornava-se importante pelo fato de transmitir em cores, ao vivo, partindo de São Paulo - Rio de Janeiro "os últimos ditames da moda, as discotecas, o culto ao corpo e a valorização dos padrões de beleza, a exaltação do individualismo e do consumismo". (NAPOLITANO, 2014, p.8).

\subsection{Contexto Econômico}

Economicamente, os anos 60 começaram em crise. Com a urbanização e industrialização resultante do Governo do presidente Juscelino Kubitscheck, no fim da década de 50, o país sofreu um declínio nas suas possibilidades de crescimento. A dívida externa estava extremamente alta em função dos empréstimos feitos para a modernização do Brasil, tendo ocorrido queda na produção interna, uma vez que a indústria nacional era limitada e sem poder competitivo, acarretando uma baixa real dos salários, desemprego e inflação.

No Planalto Central, Brasília, recém-inaugurada, atraía uma rede de novas estradas, havendo a necessidade de integração do território, que se fazia interligando ao redor da capital, todas as regiões do país. Brasília era o polo geográfico que dava sentido à interiorização, e São Paulo era 0 polo econômico em torno do qual se organizava a nova indústria, e por isso, um grande número de empresas instalou-se, principalmente na região Sudeste.

Contudo, as demais regiões brasileiras estavam à margem desse processo de industrialização, e se fazia necessário incentivar demais estados que possuíam um potencial, e ao mesmo tempo,poderiam trazer problemas ao desenvolvimento pretendido.

O economista Celso Furtado (1959) escreveu a obra "Uma política de desenvolvimento econômico para o Nordeste" e tratou de forma elucidativa sobre os problemas que assolavam a região nordestina no final da década de 50, apontando para direcionamentos necessários, entre eles, a criação da SUDENE/ Superintendência do Desenvolvimento do Nordeste, como forma de diminuir as diferenças sociais e econômicas regionais brasileiras.

Dessa forma, foi criada em 15 de dezembro de 1959, a Superintendência do Desenvolvimento do Nordeste/ SUDENE, através da Lei ${ }^{\circ} 3.692$, como uma forma de intervenção do Estado no Nordeste, com o objetivo de promover e coordenar o desenvolvimento da região, através de uma autarquia subordinada diretamente à Presidência da República, e sua secretaria executiva coube a Celso Furtado de 1959 a 1964, este foi o responsável pela estratégia de atuação do órgão, definida a partir do diagnóstico apresentado em seu livro A operação Nordeste, de 1959.

"A principal força motriz dessa conquista foi a conscientização e mobilização da sociedade brasileira, conduzida sob a liderança legítima de suas forças sociais e políticas mais representativas, quanto à 
situação de abandono secular em que se encontrava a Região, em relação às políticas nacionais de promoção do desenvolvimento, o que vinha resultando no seu atraso crescente, diante dos avanços realizados nas áreas mais desenvolvidas do País."(site da SUDENE)

Sua instituição envolveu antes de tudo, a definição do espaço que seria compreendido como Nordeste e passaria a ser objeto da ação governamental: os estados do Maranhão, Piauí, Ceará, Rio Grande do Norte, Paraíba, Pernambuco, Alagoas, Sergipe, Bahia e parte de Minas Gerais. Esse conjunto, equivalente a $18,4 \%$ do território nacional, abrigava, em 1980, cerca de 35 milhões de habitantes, o que correspondia a $30 \%$ da população brasileira. Atualmente, parte do estado do Espírito Santo também faz parte da área de abrangência da mesma.

Importante frisar que em 1959, foi elaborado um documento bastante elucidativo, pelo Grupo de Trabalho pelo Desenvolvimento do Nordeste/ GTDN que realizou um estudo que analisava sucintamente o problema que representava o nordeste no quadro de desenvolvimento nacional e propunha um conjunto de recomendações concretas, que si postas em prática, poderiam contribuir a solucionar definitivamente 0 mesmo. O documento estava dividido em quatro capítulos: o primeiro voltado para o Nordeste na economia brasileira; o segundo, para os elementos dinâmicos da economia brasileira; o terceiro tratava sobre os aspectos econômicos do problema das secas, e o quarto, para um plano de ação.

Segundo o estudo, duas causas básicas eram responsáveis pelo baixo nível de renda no nordeste brasileiro: escassez relativa do fator terra e menor acumulação do capital, apontando como verdadeira causa da economia nordestina em comparação ao centro sul brasileiro, a pobreza relativa do suporte físico. O estudo traçava paralelos entre as economias da região centro sul brasileiro e a nordestina e afirmava que o principal problema econômico brasileiro era a disparidade regional dos ritmos de crescimento.

Colocava-se no documento que a economia da região centro sul brasileira já possuía certa estabilidade devido ao nível de renda já alcançado, como também, ao ritmo de crescimento mantido, o grau de diversificação de seu parque industrial onde possuía grande expressão e a produção de bens de capital, fazendo com que essa região fosse autossustentável.

Enquanto isso, o estudo constatava que si não houvesse uma política de desenvolvimento econômico e social na região nordeste, esta poderia se transformar na "mais populosa e extensa zona subdesenvolvida do continente (GTDN, 1959, p.21)".

O plano de ações apresentado no documento girou em torno de quatro diretrizes básicas: 1) uma intensificação dos investimentos industriais na região visando criar um centro autônomo de expansão manufatureira; 2) transformação da economia agrícola na faixa úmida, com vistas a proporcionar uma oferta adequada de alimentos nos centro urbanos, cuja industrialização seria intensificada; 3) transformação progressiva da economia nas zonas semiáridas no sentido de elevar a sua produtividade e torna-la mais resistente ao impacto das secas; 4) o deslocamento da fronteira agrícola do nordeste visando incorporar as terras úmidas maranhenses que estavam em condição de receber os excedentes populacionais criados pela reorganização da economia da faixa semi árida.

A partir de 1964 a SUDENE foi incorporada ao novo Ministério do Interior, e sua autonomia, seus recursos e objetivos foram enfraquecidos e deturpados. Após décadas de funcionamento, entre erros e acertos, a instituição foi extinta através da Medida Provisória no 2.146-1 de 04 de maio de 2001- que criou a ADENE/ Agencia de desenvolvimento do nordeste.

Segundo informações contidas no site da instituição, tal decisão foi tomada sob a influência marcante da grande recessão que afetou o País a partir da década de 1980, tendo como causa remota os dois choques do petróleo ocorridos na década anterior, culminando com a cessação dos financiamentos externos e com a decretação da moratória em 1987.

"No rastro da recessão veio o ressurgimento do modelo de globalização liberalizante que havia sido abandonado após a grande depressão de 1929/1930 que deu origem às políticas de redução do tamanho e do poder de intervenção do Estado na economia, justificando a execução acelerada de amplo programa de privatização das empresas estatais e também, de modo complementar, a extinção das Superintendências de Desenvolvimento Macrorregional, que permaneciam como redutos das políticas desenvolvimentistas."

(site da SUDENE). 
No entanto, a criação da ADENE, sem a mínima condição de levar adiante a política de desenvolvimento que havia sido iniciada com sucesso pela SUDENE, sofreu severa rejeição da sociedade nordestina abrindo espaço para a discussão de propostas alternativas quanto à política de desenvolvimento regional.

Dessa forma, foi instituída a Nova SUDENE por meio da Lei Complementar № 125/ 2007, que veio em resposta aos anseios da população nordestina, manifestos no amplo processo de mobilização das forças sociais, políticas e econômicas da Região, ocorrido no período 2001/2003, " onde se tornou evidente a inadequada configuração institucional da ADENE e a necessidade de implantação de uma nova instituição de desenvolvimento regional legalmente aparelhada e administrativamente dotada de organização $e$ recursos suficientes para por em marcha uma nova sistemática de articulação interfederativa $e$ planejamento participativo capaz de promover a necessária aceleração do processo de incorporação da Região na expectativa da retomada do desenvolvimento nacional interrompido com a recessão de 1980." (site da SUDENE).

\subsection{A interferência da SUDENE em Campina Grande.}

Inicialmente, se faz necessário, contextualizar geograficamente a cidade em questão: Campina Grande está localizada no nordeste brasileiro, na região do Agreste Paraibano, no planalto da Borborema a 550m acima do nível do mar, no ponto de latitude 7ำ13'11' sul e de longitude 3552'31" a oeste; geograficamente estar bem privilegiada, situada no centro da Paraíba (figura 3). Possui uma população de 400 mil habitantes, e por ser uma cidade polo exerce grande influência sobre os aproximadamente 60 municípios que estão em seu entorno. O clima característico é o tropical semiárido, e apresenta temperaturas mais amenas devido a sua altitude. O Instituto Nacional de Meteorologia registra a média de temperatura mais alta em torno de $29,9^{\circ} \mathrm{C}$ e a mais baixa de $17,8^{\circ} \mathrm{C}$.

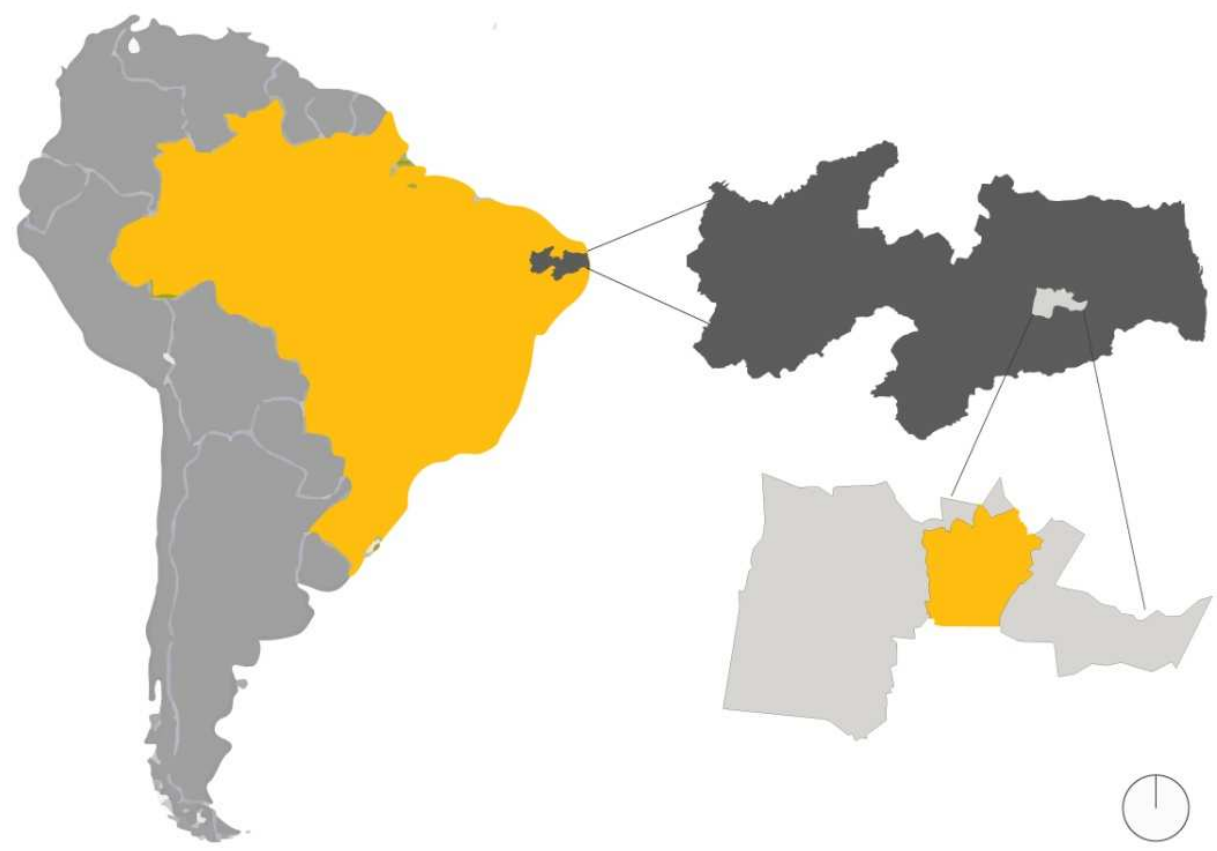

Figura 3. Mapa de localização de Campina Grande. PB. Nordeste brasileiro. Fonte: Montagem de mapas editados por Camilla Menezes.

Limita-se entre os municípios de Lagoa Seca, Massaranduba, Pocinhos e Puxinanã, ao Norte; Boqueirão, Caturité, Fagundes e Queimadas, ao Sul; Riachão do Bacamarte, a Leste e Boa Vista, a Oeste. Distam 132 km da Capital João Pessoa, posição geográfica que, segundo Oliveira (2007), a confere vantagem, em relação à distância dos principais centros do Nordeste, e tem as Rodovias Federais BR 230 (Transamazônica) e a BR 104, que atravessa a cidade no sentido Leste-Oeste e Norte-Sul respectivamente; e a BR 412, que se conecta com o Cariri Paraibano e interior de Pernambuco, como os principais acessos à sede do município. 
Segundo ALMEIDA (2011), de acordo com as REGIC - Regiões de Influência das Cidades (2007), a cidade de Campina Grande/ PB, no âmbito da rede urbana brasileira está classificada como Capital Regional B, ou seja, por estar entre as vinte cidades, com medianas de 435 mil habitantes. E, a sua classificação como Capital Regional, se justifica por ser um dos setenta centros que se ligam com o estrato superior da rede urbana, que apresenta gestão inferior ao das metrópoles, ou seja, área de influência regional, referidas como destino, para um conjunto de atividades, por grande número de municípios.

O município possui uma área territorial de aproximadamente $621 \mathrm{~km}^{2}$, apresenta 49 bairros oficiais e outros 14 novos bairros, além dos distritos administrativos de Galante, Marinho, Distrito de Catolé, Santa Terezinha, São José da Mata e Jenipapo.

$\mathrm{Na}$ década de 60, a cidade recebeu incentivos fiscais da SUDENE, que instalou no local, onze novas indústrias, e aprovou incentivos para a ampliação de dez, e reformulação de cinco. Observou-se que a geração de emprego e renda oriunda da política de industrialização regional, atrelada à política municipal, dinamizou a economia da cidade, ocorrendo o surgimento de novos bairros, e a construção de uma arquitetura que adotou uma linguagem moderna, atraindo profissionais de mais distintas cidades do país, principalmente, de Recife, Pernambuco, que construíram no local, novas paisagens urbanas modernas.

E sobre o processo de desenvolvimento econômico campinense, SILVA JUNIOR (2012) destacou que Campina Grande viveu dois ciclos econômicos importantes: o do algodão e da industrialização, sendo que esses dois ciclos mostraram-se interlaçados. As primeiras indústrias que surgiram na cidade foram com base no algodão, que no início do século XX beneficiavam-se e prensavam o algodão, e até a década de 1940 se constituíam nas principais e quase únicas unidades industriais.

Havia na cidade, uma forte tendência de crescimento voltada para a industrialização, e vários autores escreveram sobre tal fato. SILVA JUNIOR (2012) colocou que: "Antes mesmo da criação da SUDENE, a cidade mostrava a sua vocação para o setor industrial. Na década de 1940 a cidade passou a ser a única cidade do interior do Brasil, não capital de estado, que se tornou sede de um órgão de liderança do processo de industrialização do país, a FIEP, Federação das indústrias da Paraíba, onde em 17 de julho de 1949 a primeira diretoria tomou posse".

LIMA (1996) escreveu outro trabalho que tratou sobre o processo de industrialização na cidade, colocando que entre a década de 40 a 60 do século XX, o número de indústrias e de operários em Campina Grande era maior do que a capital paraibana, João Pessoa, e que nos anos de 1950-1960, atingiu no conjunto de 92 municípios nordestinos, o $4^{\circ}$ lugar em população e produção industrial da cidade. Tal processo acarretou mudanças no cenário urbano, fazendo surgir uma "nova Campina": moderna, com novas ruas, avenidas, e edificações.

A comprovação da interferência da SUDENE no desenvolvimento urbano campinense é unânime entre pesquisadores de áreas como a geografia, a história, tanto que, ALMEIDA (2011) concluiu em sua pesquisa que a causa pela qual a indústria despontou em Campina Grande, deveu-se à interferência do Estado, a começar de 1960:

"Sob as promessas econômicas da Superintendência do Desenvolvimento do Nordeste (SUDENE), a FIEP, com sede em Campina Grande, liderou um processo por distintas configurações de estímulos, o que permitiu o desenvolvimento da estrutura produtiva campinense. A SUDENE determinou a cadência de um novo crescimento urbano para Campina Grande, através do capitalismo monopolista, com a entrada de nova política industrial, o que resultou na reestruturação de Campina Grande". (ALMEIDA, 2011, p.20 ).

A autora colocou que realmente, em períodos de ditadura militar, "um conjunto de medidas de resolução fiscal, tributária e de política industrial compôs o desenvolvimento dos distritos industriais, que hoje totalizam quatro, localizados na área sul da cidade nas principais rodovias de comunicação, não havendo dispersão espacial".

O processo de industrialização evidenciado em Campina Grande acentuou-se no período denominado de Milagre Econômico. Neste momento, particularmente, a partir de 1970, o Brasil contabilizava a mudança gradual do processo econômico agrário para o agroindustrial e industrial. No caso de Campina Grande, sob o incentivo da SUDENE, verificou-se a concentração e constituição de capital para instalação do distrito industrial da cidade através de incentivos que contribuíram para torná-la no período de 1969 a 1979, um dos grandes centros da atividade industrial moderna, tanto do Estado como também do interior nordestino 
(OLIVEIRA, 2007). Esse momento histórico gerou um acervo que hoje compõe o patrimônio cultural da cidade, formando um conjunto que interagem bens do patrimônio industrial e do patrimônio moderno.

\section{TRANSFORMAÇÕE DA PAISAGEM URBANA DE CAMPINA GRANDE. UM ESTUDO DE CASO: BAIRRO DA PRATA.}

Conforme foi citado anteriormente, será tomado como estudo de caso, para observar a interferência da industrialização na cidade, a área onde foi implantado o bairro da Prata, que está localizado na zona oeste da cidade, possuindo uma área de $0,77 \mathrm{~km}^{2}$, população total de 3.884 habitantes e densidade demográfica de 561,00 hab/ km², (IBGE, 2000). Seus bairros vizinhos são: Palmeira e Monte Santo ao norte, São José ao sul, Centro a leste, e Bela Vista a oeste. (Figura 04)
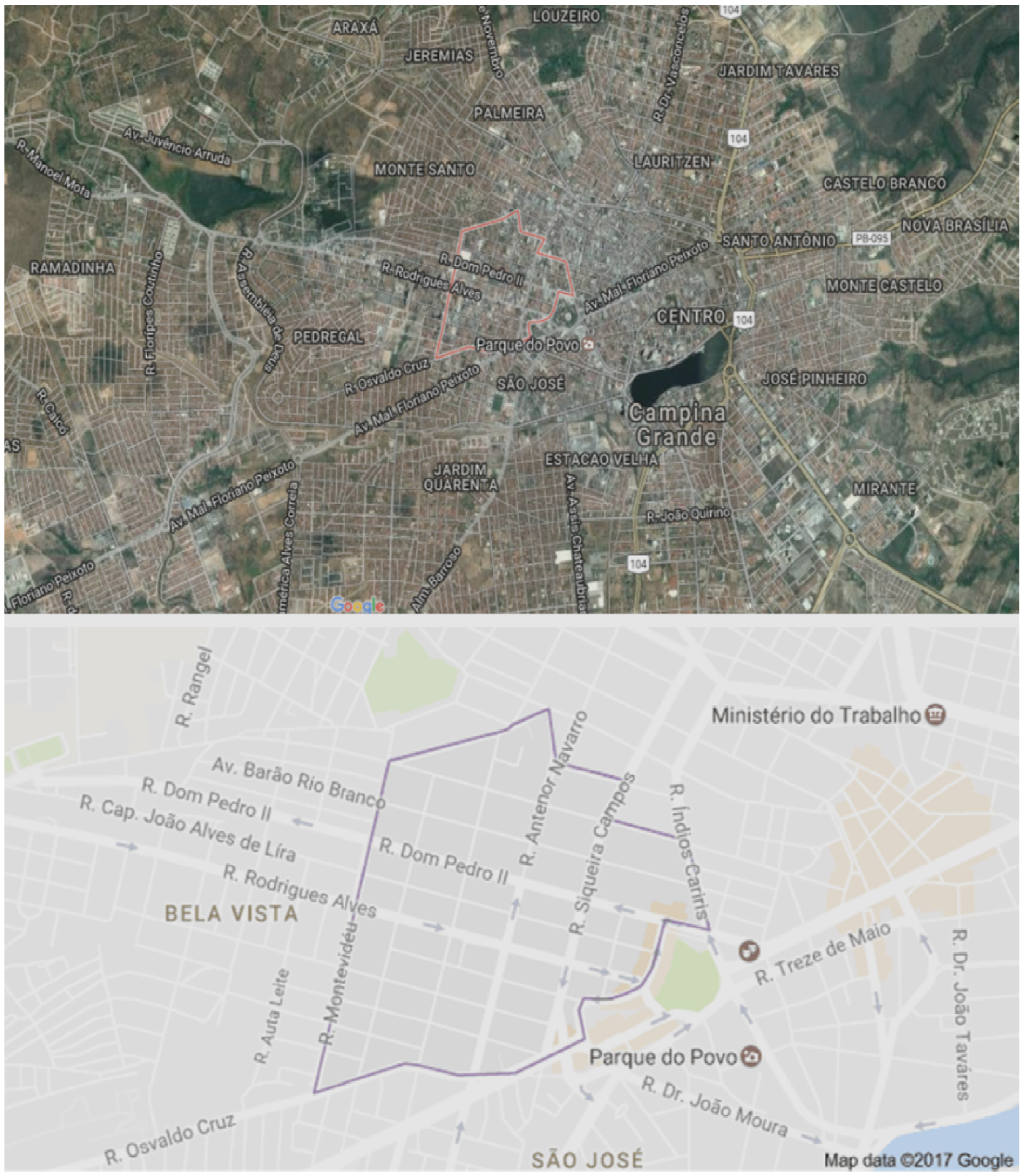

Figura 4. Mapa de localização do bairro Prata na cidade de Campina Grande.

Fonte: Montagem de mapas editados pela autora, com dados do Google maps.

A área onde foi implantado o bairro pertencia ao senhor Raimundo Viana de Macêdo (Fagundes - PB, 24 de abril de 1901 - 17 de fevereiro de 1988), que foi empresário, político e prefeito em Campina Grande, no período de 1945 até 1946. Ele era proprietário de grande parte dos terrenos onde se encontra o Bairro da 
Prata, e construiu várias edificações que colaboraram para o desenvolvimento do local, entre elas, sua própria residência, chamada "Castelo da Prata" (atualmente, demolida), o edifício Prata, localizado na Rua Semeão Leal, bem como, cedeu terrenos de sua propriedade para a construção da Igreja do Rosário e o Colégio Estadual de Campina Grande (figura 5). Era também proprietário do terreno onde foi construída a infraestrutura para a realização da conhecida "Feira da Prata".
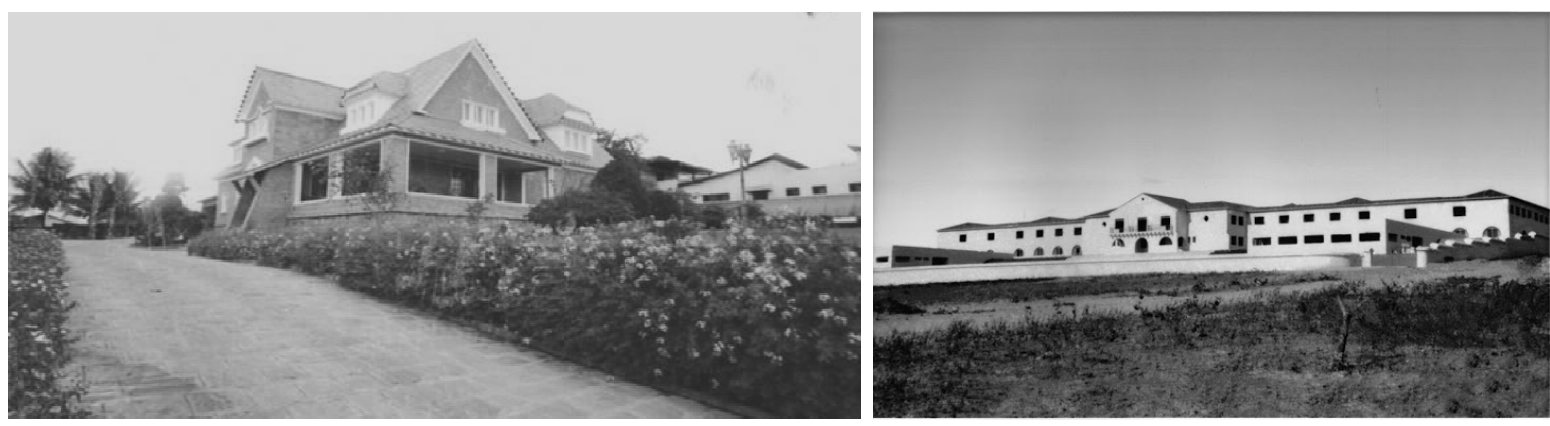

Figura 5: Castelo da Prata e Colégio Estadual de Campina Grande.

Fonte: http://cgretalhos.blogspot.com.br/2010/07/mais-sobre-o-castelo-da-prata

O bairro desde sua origem, na década de 40 , abrigou edificações de boa qualidade arquitetônica e construtiva, como o Castelo da Prata e o Colégio Estadual (atualmente, descaracterizado)- o "Estadual da Prata", maior e mais tradicional escola pública do município. Devido à sua proximidade do bairro Centro, o local recebeu uma boa infraestrutura urbana e ocupa uma colina na cidade, possuindo uma vista privilegiada.

Abriga ainda o edifício onde está implanta a "Feira da Prata" (figura 6), que é a segunda maior e mais tradicional feira de Campina Grande, funcionando todos os dias da semana, embora o dia de maior movimento aconteça mesmo aos domingos. Ela existe a mais de 50 anos e é considerada um patrimônio da história econômica, social e cultural. Ficou famosa pelo comércio de produtos regionais, principalmente do ramo de hortifrutigranjeiros, e abriga também uma série de outras atividades: barracas de artesanato, de caldo de cana com pastel, de ervas medicinais e roupas. Além dessa diversidade toda, a feira é também um importante centro gastronômico da cidade.

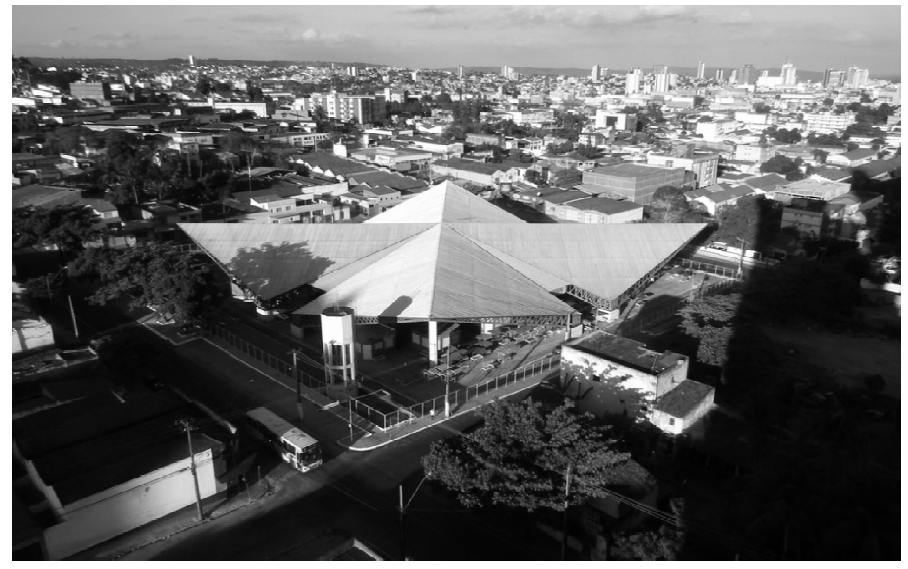

Figura 6: Feira da Prata.Edificio que abriga a venda dos produtos.

Fonte: http://cgretalhos.blogspot.com.br/2010/07/mais-sobre-o-castelo-da-prata

Nos anos 60, época de desenvolvimento econômico industrial, foi o bairro que mais se desenvolveu em termos de infraestrutura urbana, podendo-se observar um traçado de quadras regulares, ruas largas, com calçadas, praças, e um conjunto arquitetônico de residências modernas que o tornou um bairro nobre no cenário campinense.

Através de pesquisas realizadas sobre a modernidade arquitetônica na cidade (Afonso e Meneses, 2015), constatou-se que ali, foram projetadas e construídas as mais ricas residências locais, que adotaram a linguagem moderna como vocabulário plástico formal: as dezenas de casas projetadas pelo engenheiro e arquiteto autodita Geraldino Duda, nos anos 60, estavam construídas nesse bairro, conforme pode ser 
constatado no mapa. (figura 7). Enquanto a área central, localizada ao lado, se voltava para o desenvolvimento comercial, o bairro da Prata ganha um perfil residencial de alta renda.

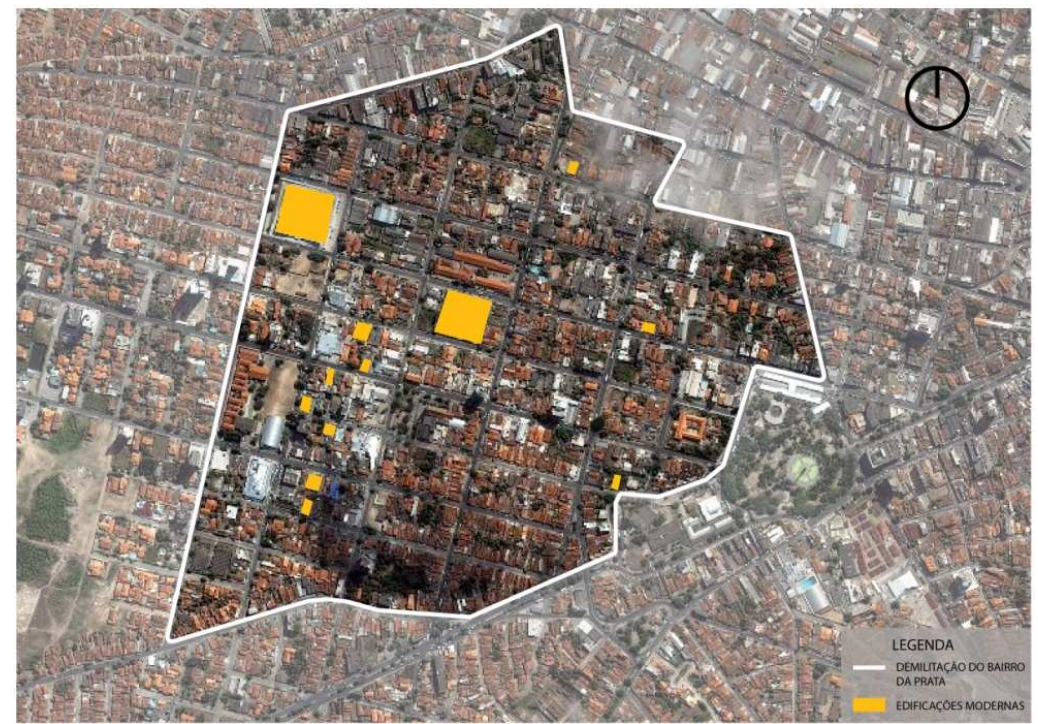

Figura 7: Feira da Prata.Edificio que abriga a venda dos produtos. Fonte:Edição de Camilla Meneses.

A curiosidade sucitada na pesquisa era entender a causa dessa ocupação e o que poderia explicar o alto padrão existente naquela produção arquitetonica local, e o tratamento urbanistico diferenciado, ordenado, e planejado daquele bairro, com quadras grandes, e ruas largas.

Somente após várias investigações, se pode constatar a relação entre o processo de urbanização do bairro, atrelado ao incremento econômico que houve na cidade. A geração de emprego e renda, o capital financeiro que entrava na cidade, era investido na construção de um bairro moderno, limpo, e organizado. Os empresários, os técnicos mais qualificados, as pessoas com uma renda maior, passaram a ocupar a área, antes considerada rural.

Para os trabalhadores das indústrias, o sistema S (formado pelo SESC, Sesi e Senai) também houve investimento naquela área, construindo-se escolas de formação e clubes para os trabalhadores. Um exempo de tal fato, foi o projeto desenvolvido pelo arquiteto Tertuliano Dionisio, inaugurado em 1962, para o Complexo arquitetônico do Clube do Trabalhador do Serviço Social da Indústria (SESI)- o Centro de Atividades Aprígio Velloso da Silveira (figura 8) - localizado na Rua Dom Pedro II do bairro. O arquiteto pernambucano Tertuliano Dionísio e o engenheiro Edson da Costa foram os responsáveis pela criação e construção dos dois volumes que abrigam a zona administrativa e a quadra poliesportiva (AFONSO e MENESES, 2016).
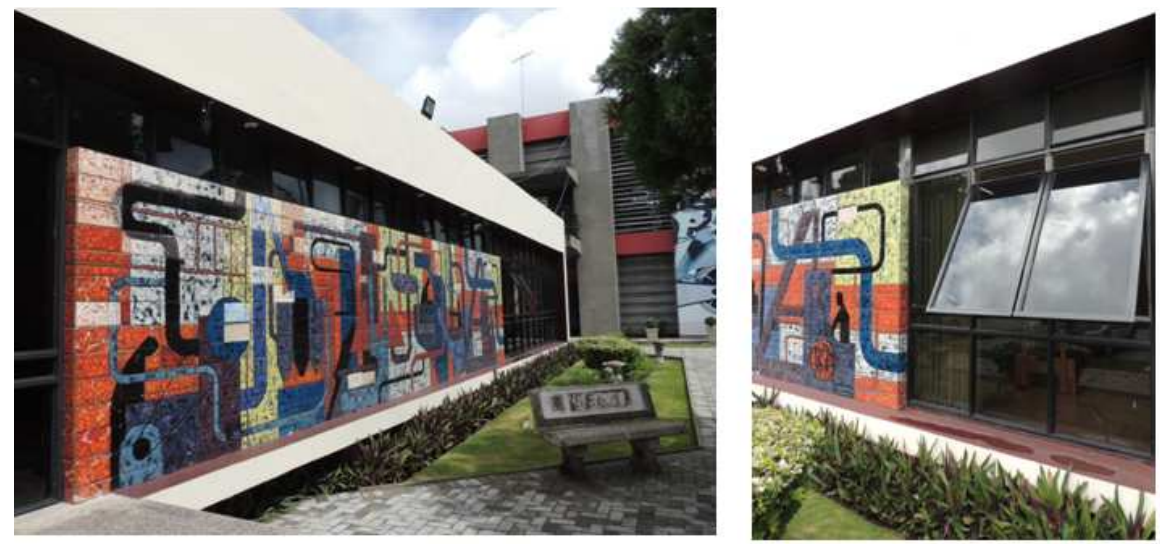

Figura 8: Clube do Trabalhador do Serviço Social da Indústria (SESI)- o Centro de Atividades Aprígio Velloso da Silveira Fonte: Foto montagem da autora. 
Pode-se observar que o bairro da Prata passou a ter um desenvolvimento urbano mais intenso, no que diz respeito a sua estrutura socioeconômica, a partir da década de 1980, com o surgimento de atividade destinada a saúde, impulsionando o bairro a uma nova função, até então existente com maior concentração no centro da cidade.

A mudança de uso do bairro, que possuía um perfil voltado para a área residencial, com o uso de uma arquitetura moderna, vem se transformando a cada dia, havendo demolições do acervo e descaracterização de edificações, que infelizmente não são protegidas por Lei (figura 9).

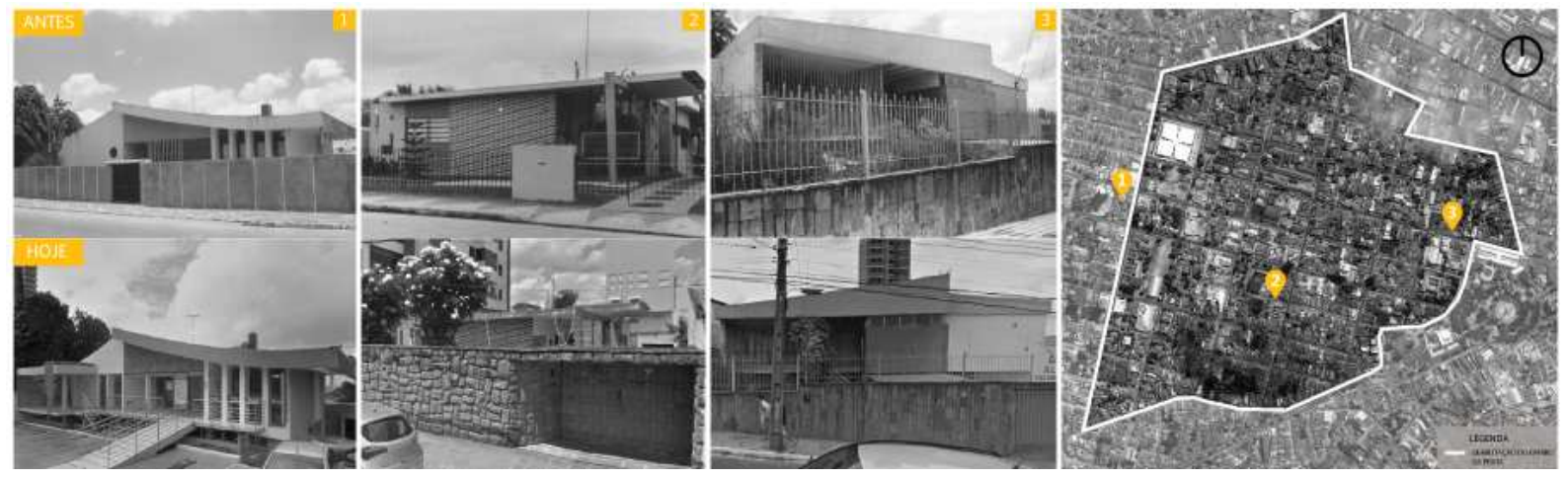

Figura 9: Residências modernas e suas transformações no bairro da Prata.

Fonte: Foto montagem de Camilla Meneses.Grupo de pesquisas Arquitetura e Lugar. UFCG

Em pesquisa realizada sobre o bairro da Prata, APOLINÁRIO (2011) escreveu que:

"À medida que esse processo de urbanização vem crescendo no bairro, os elementos espaciais vão se moldando as novas funções, que surgem a partir de um processo de acumulação e concentração do capital, gerando uma dinâmica econômica que rege a mudança da sociedade de acordo com o modo de produção capitalista. Sendo assim, o bairro passa por uma transformação bastante visível em sua paisagem, na medida em que é visto como um espaço urbano com um grande potencial imobiliário, tomando como princípio não só o fato do bairro ser considerado classe média alta, desde sua formação, mas também sua acessibilidade e localização na cidade."

A localização próxima ao Centro urbano influi diretamente na questão da especulação imobiliária presente no bairro da Prata, promovendo ainda mais sua valorização, podendo-se observar na atualidade uma mudança drástica no cenário urbano local, apagando da memória coletiva, a produção moderna de Campina Grande. O bairro que foi palco para a construção de obras modernas, oriundas dos investimentos no setor industrial em Campina Grande, devido a não estar inserido no perímetro do centro histórico, não está protegido das transformações urbanas contemporâneas.

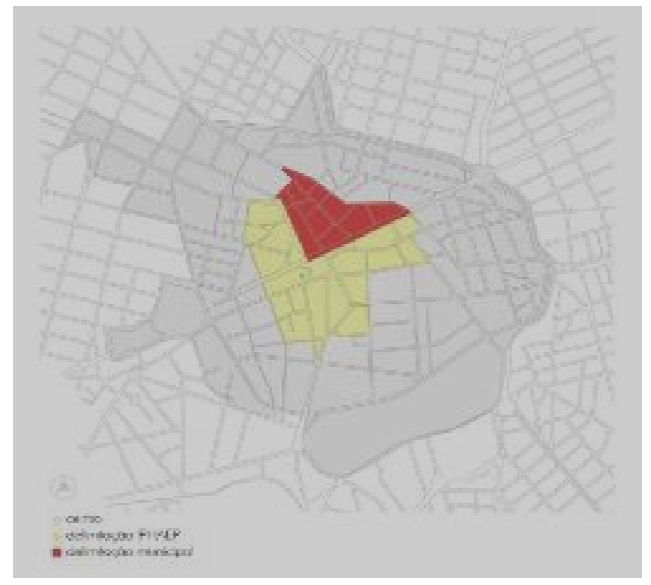

Figura 10: Mapa de localização do Centro histórico de Campina Grande. PB. Fonte: Arquivo do Grupo de Pesquisa Arquitetura e Lugar. CAU. UAEC. CTRN. UFCG 
O Centro Histórico de Campina Grande é uma área deliberada (em 2003) e delimitada pelo Conselho de Proteção dos Bens Históricos (CONPEC) do Instituto do Patrimônio Histórico e Artístico do Estado da Paraíba (IPHAEP) em 28 de junho de 2004, compreendendo um cinturão englobando ruas e praças centrais da cidade. Porém, seu tombamento não tem impedido que seus prédios e monumentos fossem destruídos pela voracidade do "progresso", desfigurando o patrimônio histórico da cidade, conforme colocaram os pesquisadores OLIVEIRA e SANTOS (2011, p.64).

\section{CONCLUSÂO}

Conforme foi visto anteriormente, o bairro da Prata desde os anos 80 do século XX vem passando por um acelerado processo de mudança de uso, e a região vem tendo seus imóveis modernos demolidos ou descaracterizados para abrigar clínicas, hospitais, escolas ou edifícios multifamiliares de alto padrão. Existem poucos terrenos vazios no local e o metro quadrado vem a ser um dos mais valorizados na cidade, devido à infraestrutura urbana de serviços públicos que a prefeitura proporcionou ao bairro desde a sua origem.

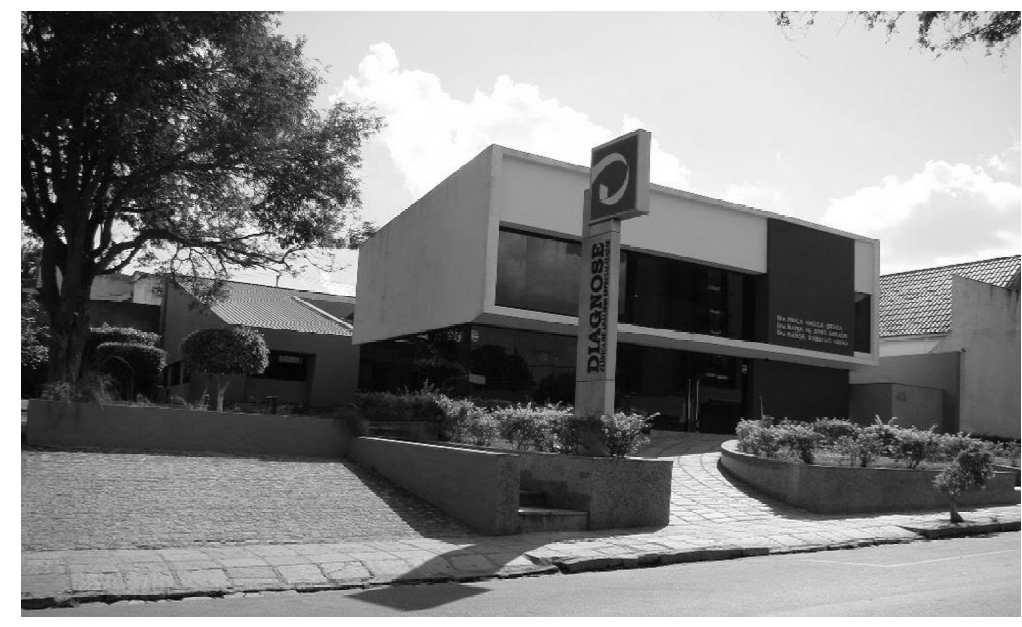

Figura 11: Descaracterização do acervo moderno do bairro da Prata: novos usos

Fonte: Arquivo do Grupo de Pesquisa Arquitetura e Lugar. CAU. UAEC. CTRN. UFCG.

Sem proteção legal, pois fica fora do perímetro urbano tombado pelo IPHAEP, o bairro dificilmente conseguirá preservar sua arquitetura, produzida no apogeu do período de industrialização que houve em Campina Grande. As residências projetadas por Geraldino Duda nos anos 60, concentradas no bairro, já foram quase em sua totalidade demolidas ou transformadas para os novos usos.

Observou-se na pesquisa, que em nível municipal, existe um departamento que tenta desenvolver um trabalho de educação patrimonial, dialogando com o IPHAEP/Instituto de Patrimônio Histórico e Artístico do Estado da Paraíba, com a UFCG/ Universidade Federal de Campina Grande e com a Universidade Estadual da Paraíba, no sentido de buscar parcerias e se fortalecer no trabalho de preservação do acervo.

Porém, na cidade observa-se certa inércia na área de políticas públicas preservacionistas. A discussão da preservação é vista sob o ponto de vista apenas cultural e não, de planejamento urbano, como propõe uma política preservacionista que trabalha com o conceito de conservação integrada $(\mathrm{Cl})$ territorial e urbana.

ZANCHETTI (2002) colocou em seu texto que a Cl deve ser a estratégia de planejamento e gestão utilizada em áreas urbanas consolidadas que sejam reconhecidas como de interesse patrimonial-cultural, isto é, nessas áreas o processo de desenvolvimento privilegiará a conservação do patrimônio cultural, relativamente ao processo de transformação urbana; Aqui, a conservação é entendida como uma forma especial do processo de transformação urbana que procura manter no tempo (intergerações) a integridade e a autenticidade do patrimônio cultural, buscando o desenvolvimento sustentável, inserindo a conservação do patrimônio-cultural urbano, como um ativo que agrega valor em todas as dimensões do desenvolvimento (econômica, política, cultural, ambiental e físico-espacial).

A questão trata-se de uma série de fatores que não colaboram para o processo de preservação do acervo moderno arquitetônico e urbano, e entre eles pode-se citar a falta de conhecimento das instituições e da 
comunidade, a respeito da importância do mesmo. As instituições públicas criaram mecanismos legais para a preservação de parte do acervo local, através da Lei Municipal no 3721/1999 que tratou da zona especial de preservação 1, e do Decreto Estadual no 25.139/2004, mas contatou-se que estas beneficiam apenas o acervo em estilo Art Déco existente na área central urbana.

Através do Instituto do Patrimônio Histórico e Artístico do Estado da Paraíba- IPHAEP, dezoito imóveis desse acervo, encontram-se tombados em nível estadual, enquanto que o IPHAN/ Instituto de Patrimônio Histórico e Artístico Nacional, não realizou nenhum tombamento, ainda, na cidade. Observa-se que intervenções práticas de restauração e revitalização das obras arquitetônicas não vêm sendo realizadas. A prioridade da preservação está voltada para o acervo de Art Déco, e para imóveis isolados concentrados na área do Centro histórico.

As transformações urbanas decorrentes de uma necessidade de reutilização dos espaços existentes, e dos novos programas do século XXI são possíveis serem realizadas de forma consciente, desde que os agentes envolvidos nesse processo tenham consciência do valor histórico do local e o respeite em suas intervenções. A cidade não pode ficar "engessada", e essa discussão é antiga. Mas, também não pode ser descaracterizada, demolida, pela falta de diálogos entre as distintas dimensões do espaço urbano. O diálogo entre cultura, arquitetura e economia é imprescindível.

O que restará na história urbana campinense dessa fase áurea da industrialização? Diversos espaços industriais foram substituídos por novos usos; os bairros que guardavam parte dessa história também. Esse conjunto que interagem bens do patrimônio industrial e do patrimônio moderno vem sendo perdido de forma rápida.

São duas categoriais de bens patrimoniais que se encontram à margem das prioridades preservacionistas nacionais, inexistindo inventário dos mesmos, e a inserção deles no rol dos bens que devem ser preservados.

Dessa forma, a academia através de pesquisas e ações na área de educação patrimonial vem procurando provocar os atores privados e públicos para a inserção desses na agenda política municipal, a fim de conservar de forma integrada os espaços de interesse cultural no planejamento urbano local.

\section{BIBLIOGRAFIA}

AFONSO, A. (2015). Liverpool do Brasil. Resquícios do Patrimônio industrial em Campina Grande. Proposta para novo uso de antiga estrutura industrial. Gijón: Anais da VII Jornadas Internacionais de Patrimônio Industrial.

AFONSO, A. e MENESES, C (2015). A Influência da escola do recife na arquitetura de Campina Grande 1950-1970. Belo Horizonte: Anais do 4ํㅗㄴ Seminário lbero americano de Arquitetura e Documentação.

AFONSO, A. e MENESES, C (2016). Análise projetual do complexo arquitetônico do Clube do Trabalhador do Serviço Social da Indústria (SESI). Campina Grande. PB. 1962-1990. Teresina: Anais do 6o Docomomo Norte Nordeste.

ALMEIDA, Maria do Socorro Nicolly Ribeiro de (2011). Relações socioespaciais no contexto das indústrias de calçados informais de Campina Grande: Paraíba. João Pessoa: Dissertação de mestrado em Geografia. UFPB.

ALVES, Leonardo da Silva. (2012). A industrialização incentivada do nordeste e o caso de Campina Grande. PB. Campina Grande. Dissertação de mestrado apresentada no Programa de pós graduação em desenvolvimento regional. Universidade Estadual da Paraíba.

APOLINÁRIO, Otávia et alli. (2011). Especulação e verticalização: reflexos na paisagem do bairro da prata em campina grande-pb e o uso do georreferenciamento. Anais do 9o Encontro latino Americano de pós graduação e iniciação cientifica. UNIVAP.São José dos Campos.SP.

CASTRIOTA, L. B. (2009). Patrimônio cultural. Conceitos, políticas, instrumentos. São Paulo: Anablume. 
Carta de Nizhny Tagil Sobre o Patrimônio Industrial. The International Committee for the Conservation of the Industrial Heritage (TICCIH)Nizhny Tagil, 17 de Julho de 2003.Em rede: http://ticcih.org/wpcontent/uploads/2013/04/NTagilPortuguese.pdf.Acessado em 20 de junho de 2015.

CHOAY, F.(2006). A Alegoria do Patrimônio. 4ạ. Ed. São Paulo: Estação Liberdade. UNESP.

CURY, I. (2000). Cartas Patrimoniais. Rio de Janeiro: IPHAN/ Deprom.

FURTADO, Celso (1959). Uma política de desenvolvimento econômico para o Nordeste. Rio de Janeiro: Imprensa Nacional.

GASTÓN,C; ROVIRA,T.(2007) El proyecto Moderno: Pautas de Investigación. Barcelona: Ediciones UPC.

GOITIA, Fernando Chueca. (2011). Breve Historia del Urbanismo. Madrid: Alianza Editorial.

LIMA, Damião. (1996). O Processo de industrialização via incentivos fiscais: expansão e crise em Campina Grande. Dissertação de mestrado em Economia Rural.UFCG.

NAPOLITANO, Marcos (2014). História do Regime militar brasileiro. São Paulo: Editora Contexto.

OLIVEIRA, Thomas Bruno e SANTOS, Juvandi de Souza. Centro Histórico de Campina Grande: a cartografia de uma destruição. TARAIRIÚ - Revista eletrônica do Laboratório de Arqueologia e Paleontologia da UEPB. Campina Grande, Ano I - Vol. 1 - Número 01 - Setembro de 2010.p.64

PORTELLI, A. História Oral e Poder (Conferência no XXV Simpósio Nacional da ANPUH, Fortaleza, 2009) em rede: http://www.mnemosine.cjb.net/mnemo/index.php/mnemo/article/view/424/682. Acesso no dia 4 de maio, às $22 \mathrm{hs}$.

SERRA, Geraldo. (2006). Pesquisa em arquitetura e urbanismo. Guia prático para o trabalho de pesquisadores em pós graduação. São Paulo: EDUSP.

ZANCHETTI, Silvio. (2006) A conservação integrada e o desenvolvimento sustentável. Em rede: http://conservacaourbana.blogspot.com.br/2006/06/conservao-integrada-e-o.html monday, june 192006.

O Brasil de JK > A criação da Sudene

http://cpdoc.fgv.br/producao/dossies/JK/artigos/Economia/Sudene Lúcia Lippi Oliveira 